\title{
Layanan Servis Sepeda Motor Gratis Di Masa Pandemi Covid-19
}

\author{
Anas Mukhtar ${ }^{1}$, Ikhwanul Qiram ${ }^{2 \bowtie}$ \\ ${ }^{1,2}$ Program Studi Teknik Mesin, Fakultas Teknik, Universitas PGRI Banyuwangi \\ Email: anasmukhtar@unibabwi.ac.id ${ }^{1}$,ikhwanulqiram@uniba-bwi.ac.id ${ }^{2}$
}

\begin{abstract}
Abstrak - Pada rogram pengabdian ini merupakan bentuk kegiatan rutin tahunan yang telah ditetapkan sebagai bentuk sumbangsih Fakultas Teknik, Program Studi Teknik Mesin Universitas PGRI Banyuwangi. Tujuan kegiatan ini merupakan bagian dari upaya untuk mengurangi beban ekonomi masyarakat di masa pandemi Covid 19. Metode pelaksanaan dilakukan secara langsung dimana masyarakat diberikan informasi melalui media tentang layanan servis sepeda motor gratis dengan tetap mematuhi protocol pencegahan penularan Covid 19. Kegiatan ini juga menjadi bagian dari upaya pengembangan skill mahasiswa teknik mesin Universitas PGRI Banyuwangi.
\end{abstract}

Kata Kunci - Servis Gratis, Sepeda Motor, Pengabdian Kepada Masyarakat, Covid-19

Abstract - This service program is a form of annual routine activity that has been designated as a form of contribution from the Faculty of Engineering, Mechanical Engineering Study Program, PGRI University of Banyuwangi. The purpose of this activity is part of an effort to reduce the economic burden of the community during the Covid 19 pandemic. The method of implementation is carried out directly where the public is given information through the media about free motorcycle service services while adhering to the protocol for preventing the transmission of Covid 19. This activity is also part of the efforts to develop the skills of mechanical engineering students at the PGRI Banyuwangi University.

Keywords - Free Service, Motorbikes, Community Service, Covid-19

\section{Pendahuluan}

Mengacu data dari AISI (Asosisasi Industri Sepeda Motor Indonesia), hingga juni 2010 jumlah penjualan sepeda motor mencapai 40 Juta Unit dan mengalami peningkatan prosentase sekitar $12.5-15 \%$ pertahun. Pertumbuhan jumlah sepeda motor yang sangat pesat diikuti dengan pertumbuhan jumlah kecelakaan yang tinggi pula. Kecelakaan kendaraan di jalan raya didominasi oleh pengendara sepeda motor yaitu sebesar 70\% [1].

Beberapa faktor penyebab terjadinya kecelakaan di jalan raya adalah faktor pengemudi, infrastruktur jalan, dan kendaraan. Faktor pengemudi misalkan saja mengendarai kendaraan dalam keadaan mengantuk, mabuk, atau mengendarai tanpa mematuhi peraturan keselamatan berlalu-lintas. Sedangkan faktor infrastruktur jalan yaitu kualitas jalan yang jelek, banyak lubang, atau daya tampungnya tidak sesuai dengan jumlah kendaraan yang melaluinya. Sementara faktor kendaraan yaitu rem yang tidak bekerja, ban aus, kemudi yang sudah tidak bekerja dengan normal, dan kerusakan pada bagian-bagian yang menyebabkan kendaraan sulit dikendalikan sesuai dengan keinginan pengendara. Kerusakankerusakan yang terjadi pada kendaraan dan tidak segera diatasi menjadi salah satu faktor penyebab terjadinya kecelakaan.
Kondisi kendaraan yang tidak normal menjadi salah satu faktor penyebab terjadinya kecelakaan. Akan tetapi pemilik kendaraan masih sering mengabaikan kerusakan yang terjadi pada kendaraannya dan tidak segera melakukan perbaikan. Kendaraan yang rusak akan tetapi tidak segera diperbaiki disebabkan faktor keuangan, faktor ketersediaan bengkel, dan faktor ketidaktahuan pemilik kendaraan. Menurut data AISI, jumlah bengkel resmi Honda: 3.800 AHASS, Yamaha: 2.750 YSS, dan Suzuki: 1.400. Jumlah totalnya iika ditambah dengan bengkel kawasaki, Piagio, TVS, Bajaj, Minerva, dan KTM masih di bawah 10.000 bengkel. Bengkel-bengkel tersebut adalah bengkel resmi yang tergabung atau mendapatkan lisensi dari Agen Tunggal Pemegang Merk (ATPM). Jika perbandingan antara jumlah bengkel resmi dengan yang diluar ATPM adalah 1:5, maka jumlah bengkel sepeda motor adalah 50.000 bengkel. Dengan demikian perbandingan antara jumlah kendaraan dengan bengkel untuk perbaikan adalah: 50.000: 40.000.000 atau 1:800. Artinya 1 bengkel melayani 800 sepeda motor. Sebagai dampaknya, pemilik kendaraan harus antri dalam melakukan perawatan kendaraan dan mengabaikan kerusakan yang terjadi.

Sedangkan kerusakan kendaraan akan tetapi tidak segera dilakukan perbaikan karena faktor ketidaktahuan pemilik kendaraan juga banyak terjadi. 
Walaupun setiap sepeda motor yang dijual dari dealer dilengkapi dengan petunjuk perawatan sederhana, akan tetapi karena tidak memiliki ketrampilan teknisnya maka pemilik kendaraan juga tidak pernah melakukan perawatan sesuai dengan ada yang dibuku petunjuk. Akibatnya, kita dapat dengan mudah menemukan sepeda motor dengan kondisi rem yang tidak standar, ban aus atau tekananya tidak sesuai spesifikasi, lampu indikatornya mati, kopling berat, stang tidak stabil dan berbagai kerusakan lain yang dapat membahayakan pemilik kendaraan saat mengendarainya di jalan. Kegiatan servis gratis sepeda motor ini perlu diadakan berdasarkan latar belakang yang dipaparkan di atas. Kegiatan servis gratis juga menjadi salah satu bentuk implementasi ilmu oleh dosen dan mahasiswa yang dikembangkan dikampus dan memberikan manfaat secara langsung kepada masyarakat.

Sejak pandemi covid-19 berbagai upaya penanggulangan dilakukan pemerintah untuk meredam dampak dari pandemi covid-19 di berbagai sektor. Hampir seluruh sektor terdampak, tidak hanya kesehatan, sektor ekonomi juga mengalami dampak serius akibat pandemi covid-19. Jenis usaha yang mengalami dampak secara signifikan adalah bidang transportasi dan jasa umum lainnya. Dengan biaya operasional yang tinggi terkadang memicu masyarakat untuk mengabaikan pemeliharaan sarana transportasi yang mereka gunakan. Kondisi ini berdampak terhadap menurunnya fungsi akibat kerusakan komponen dan dan berakibat fatal bagi pengguna kendaraan. Kegiatan ini juga merupakan ajang mengenalkan potensi dan keterampilan yang dimiliki oleh Program Studi Teknik Mesin Fakultas Teknik Universitas PGRI Banyuwangi.

\section{SOLUSI DAN LUARAN}

Dari potensi dan hambatan diatas, program yang dilakukan adalah melaksanakan kegiatan servis gratis selama dua hari, kegiatan ini diperuntukkan bagi masyarakat umum khususnya bagi pengguna roda dua aktif seperti gojek, pedagang pasar dan lain sebagainya. Kegiatan servis ini didukung melalui beberapa mitra Pogram Studi Teknik Mesin Universitas PGRI Banyuwangi yang meliputi, Honda AHM, SMK Muhammadiyah 2 Genteng, Ikatan Alumni Teknik Mesin, serta beberapa sponsor lainnya.

\section{Metode Kegiatan}

Kegiatan dilakukan pada tanggal 11-12 Desember 2020 dengan tahapan sebagai berikut :

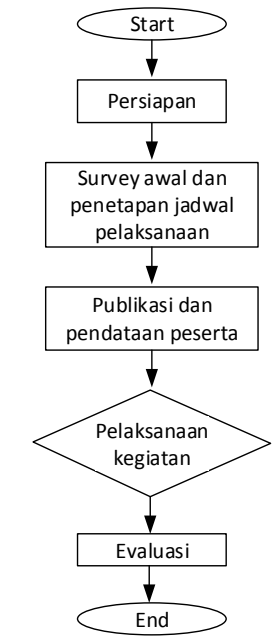

Gambar 1. Alur pelaksanaan kegiatan PKM

Servis sepeda motor dilakukan selama dua (2) hari. Empat (4) buah pit/line untuk melayani servis disediakan dalam kegiatan servis sepeda motor. Setiap pit dilengkapi dengan peralatan untuk servis dan 2 orang mekanik. Setiap pit ditargetkan dapat mengerjakan 7 buah sepeda motor/hari. Selain mekanik, dalam kegiatan servis gratis juga terdapat bagian adminstrasi untuk mencatat pendaftar dan keluhan-keluhan pada sepeda motor yang akan diperbaiki serta seorang servis advisor yang bertanggung jawab terhadap kualitas hasil pekerjaan mekanik. Langkah-langkah/prosedur pelaksanaan servis sepeda motor adalah sebagai berikut:

- $\quad$ Langkah 1

Pemilik sepeda motor mendaftarkan kendaraannya pada bagian administrasi dilengkapi dengan keluhan-keluhan kerusakan yang terjadi. Selanjutnya pemilik sepeda motor dipersilahkan untuk menunggu kendaraan di service. Saat yang sama pemilik sepeda motor bisa memanfaatkan tempat istirahat yang nyaman dengan fasilitas yang diberikan.

- $\quad$ Langkah 2

Sepeda motor yang sudah diperbaiki dicek terlebih dahulu oleh service advisor sebelum diserahkan kembali kepada konsumen.

\section{HaSil Kegiatan}

Pelaksanaan servis gratis sepeda motor ini mendapat respon yang sangat positif dari peserta dengan indikasi peningkatan jumlah peserta pada hari kedua sehingga harus dibatasi. Mahasiswa yang bertindak sebagai mekanik juga mempunyai keuntungan dalam kegiatan servis sepeda motor. Mahasiswa dapat mengaplikasikan keilmuan yang dipelajari dari bangku kuliah dan menambah jam terbang dalam kompetensi perawatan sepeda motor. Kemampuan mahasiswa dalam berkomunikasi dengan peserta juga dikembangkan melalui tuntutan 
peserta servis gratis yang menginginkan sepeda motornya diservis secara maksimal.

Di kegiatan servis gratis ini, penyelenggara juga menyediakan pelayanan ganti oli. Pelayanan ini tidak cuma-cuma. Selain itu pelayanan juga dilengkapi dengan beberapa komponen motor (spare part) yang umum yang sering dibutuhkan dalam perbaikan seperti seal, mur baut dan lain -lain.

Faktor pendukung pelaksanaan program servis gratis dan pelatihan perawatan sepeda motor yaitu:

1) Lokasi pelaksanaan servis gratis luas sehingga leluasa dalam membuat setting pelayanan servis. Stand pendaftaran dan 4 stall servis serta tempat parkir yang luas bagi peserta yang antri untuk mendapatkan pelayanan servis gratis.

2) Mahasiswa yang bertindak selaku mekanik adalah mahasiswa yang mempunyai kompetensi servis baik dan mempunyai jam terbang yang cukup dalam melakukan servissepeda motor.

3) Peralatan yang berupa empat set toolbox, satu unit kompresor, dan peralatan khusus lainnya bisa diperoleh dari mitra yang sudah menjadi pendukung atas terselenggaranya kegiatan ini.

4) Tingginya antusiasme peserta untuk mendapatkan pelayanan servis gratis sehingga target dapat tercapai dan bahkan harus membatasi jumlah peserta pada hari yang kedua.
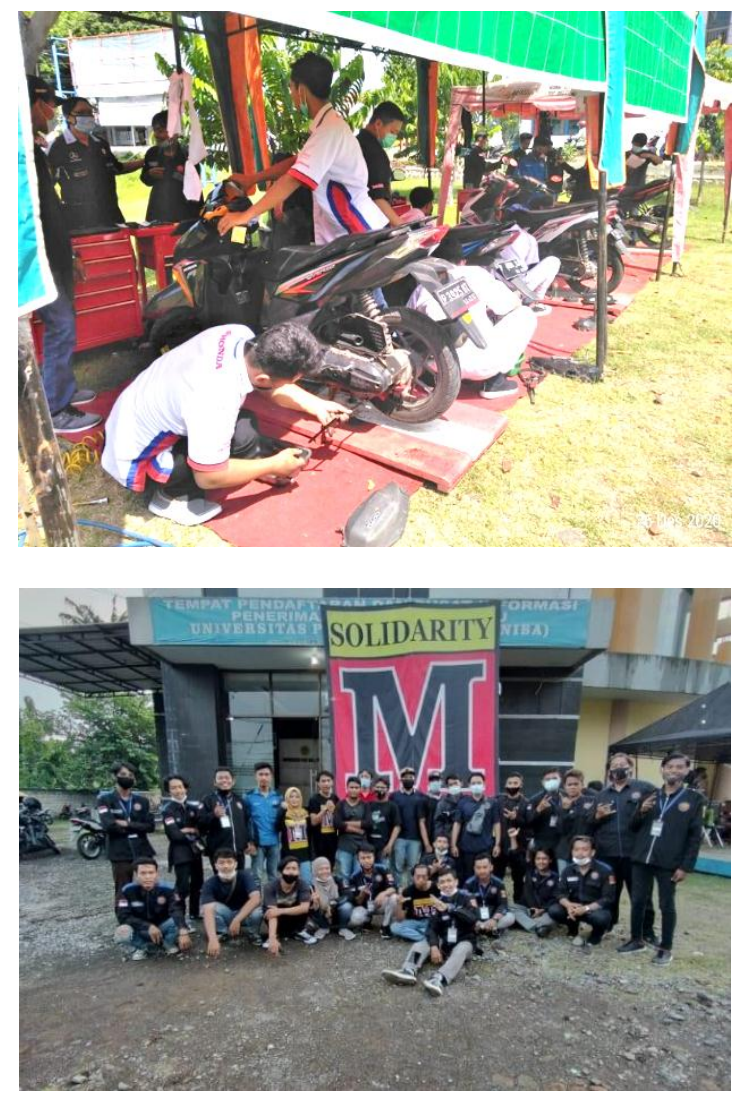

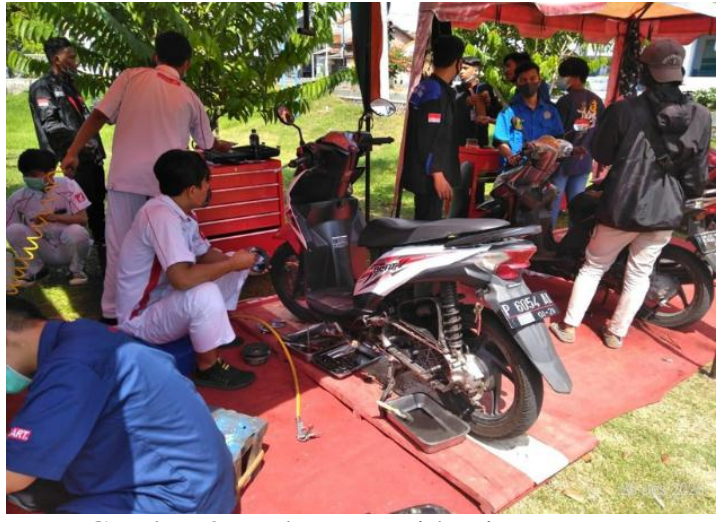

Gambar 2. Dokumentasi kegiatan PKM Servis Gratis

\section{KESIMPULAN}

Hasil kegiatan menunjukkan tingginya antusias masyarakat untuk mengakses layanan service gratis. Di sisi lain, mahasiswa memiliki kemampuan dalam melakukan service ringan dengan memanfaatkan pengetahuan dan keterampilan yang diperoleh di kampus. Kegiatan servis gratis sepeda motor dapat dilaksanakan secara rutin setiap tahun untuk memberikan pengetahuan kepada masyarakat tentang pentingnya perawatan berkala dan pengetahuan dasar perawatan sepeda motor. Sosialisasi kegiatan servis gratis dan pelatihan perawatan sepeda motor ditingkatkan sehingga cakupan peserta dapat lebih luas.

\section{UCAPAN TERIMA KASIH}

Penulis mengucapkan terimakasih kepada Rektor Universitas PGRI Banyuwangi, Dekan Fakultas Teknik beserta jajarannya. Ucapan terimakasih juga disampaikan kepada segenap mitra dan alumni serta mahasiswa tenik mesin Universitas PGRI Banyuwangi dalam dukungannya pada Program Kemitraan bagi Masyarakat tahun 2020.

\section{DAFTAR PUSTAKA}

[1]. Astra Honda Training Center. (2005). Pelatihan Mekanik tingkat I. Modul.

[2]. M. Setyo, 2016, Pengertian dan Manfaat Tune Up Sepeda Motor, http;//www.guruotomotif.com

[3]. PT. Astra Honda Motor. (2005). Buku Pedoman Pemilik Honda. Jakarta. Sudiyanto, Sudarwanto, Y. G. Sampurno, I. Siswanto, 2013, Pelatihan

[4]. Perawatan dan Servis Gratis Sepeda Motor Dalam Rangka Dies Natalis UNY ke-Tahun 2013, Lembaga Penelitian dan Pengabdian Kepada Masyarakat Universitas Negeri Yogyakarta.

[5]. V. Suhendra, 2013, Tune Up (Service) Sepeda Motor, http://www.vonnysuhendra.blogspot.co.id 